\title{
NORTHEASTERN UNITED STATES SPECIES TREATED WITH COPPER-BASED PRESERVATIVES: DURABILITY IN MISSISSIPPI STAKE TESTS
}

\author{
Stan T. Lebow ${ }^{1, \mathrm{~s}}$, Rachel A. Arango ${ }^{1}$, Patricia K. Lebow ${ }^{l}$,Grant T. Kirker ${ }^{l}$, \\ Mark E. Mankowski ${ }^{1}$, Steven A. Halverson ${ }^{I}$
}

In memoriam of Dr. Thomas C. MANNES

\begin{abstract}
This paper reports on the ground-contact durability of lesser-used wood species of the northeastern United States after treatment with copper-based preservatives. Stakes $(19$ x 19 x $457 \mathrm{~mm})$ cut from balsam-fir (Abies balsamea), eastern hemlock (Tsuga canadensis), eastern spruce (mixture of Picea glauca, Picea mariana and Picea rubens), red maple (Acer rubrum) or eastern white pine (Pinus strobus) were treated with one of four concentrations of chromated copper arsenate type C (CCA-C), copper citrate (CC), alkaline copper quat type C (ACQ-C) or copper azole type A (CBA-A) and placed into the ground at a test site in southern Mississippi. Similarly treated southern pine (Pinus spp.) stakes were included for comparison. The stakes were rated for decay and termite attack after 1, 2, 3, 4, 5, 8, 10 and 12 years. Eastern white pine and incised eastern hemlock and balsam-fir had durability similar to southern pine when treated with CCA or the other copper-based preservatives. Eastern spruce was less durable than the other softwood species, apparently because of low preservative uptake. Red maple had the least durability at all retentions and for all preservatives. This study indicates that several northeastern softwoods can be adequately durable when pressure-treated with CCA-C or copper-based preservatives.
\end{abstract}

Keywords: Decay, ground contact, preservative treatment, underutilized species, termites.

\section{INTRODUCTION}

The volume of available timber in the northeastern and northcentral United States has been increasing for several decades (Smith et al. 2009). Unfortunately, a disproportionate amount of this growth has occurred in wood species that are considered of low commercial value. There has been a particularly large increase in the proportion of red maple relative to more traditionally valuable species such as red oak, white oak, and the hard maples (Alderman et al. 2005, Fei and Steiner 2007). Although red maple is the most consistent example of increased growth, the volume of eastern white pine in Wisconsin nearly tripled between 1983 and 2013 (Anon 2014). Other lesser-used softwood species, such as hemlock and spruce have also shown an increase in volume, but to a lesser extent. Recent reports from New York State (Anon 2015a) and southern New England (Anon 2015b) indicate that the saw timber value of red maple is only $20-50 \%$ that of hard maple or red oak, while the value of white pine, eastern hemlock or eastern spruce is only $10-30 \%$ of the other, more valuable hardwoods. Adding value to these wood species would give forest managers more flexibility in economically managing the forest resource while preserving more traditional commercial species. A potential path for adding value to these lesser-used species is to demonstrate the feasibility of their use in structures built from pressure-treated lumber. However, before a wood species can be accepted in this market, adequate 
penetration and retention of the preservative must be determined and the preservative treatment must be evaluated for durability against biodeterioration.

Research examining preservative treatment of various northeastern wood species has been examined in previous studies, primarily using CCA-C (Gjovik and Schumann 1992, Morris et al. 2017, Richards and Inwards 1989, Richards and McNamara 1997, Smith 1986, Smith et al. 1996). As a result of these studies and further unpublished efforts, eastern hemlock was added to the American Wood Preservers Association (now American Wood Protection Association) Book of Standards in 1997, and the incising requirement for eastern white pine was modified for treatment with CCA (AWPA 1997). However, the types of preservatives used commercially have changed greatly since that time. For treatment of dimension lumber, CCA-C has largely been replaced with copper-based systems that do not contain chromium or arsenic. The chemistry of these newer wood preservatives is substantially different than that of CCA-C, yet there is relatively little published research on their ability to treat and protect northeastern wood species. To address these concerns, a research project was conducted with the cooperative efforts of the USDA Forest Products Laboratory (FPL), USDA State and Private Forestry, Northeastern Forest Alliance, Vermont Department of Forest, Parks and Recreation, preservative manufacturers and cooperating lumber producers in the Northeast. The wood species selected for evaluation were balsam fir (Abies balsamea), eastern hemlock (Tsuga canadensis), red maple (Acer rubrum), eastern white pine (Pinus strobus) and eastern spruce (a mixture of white (Picea glauca), black (P. mariana), and red (P. rubens) spruce). An evaluation of species treatability was conducted, and field tests were initiated to evaluate durability for both above-ground and groundcontact application (Lebow et al. 2005, Lebow et al. 2010a, Lebow and Halverson 2015).

Evaluation of preservative retention and penetration in the northeastern species examined indicated that treatment with arsenic- and chromium-free alternatives were comparable to CCA-C, and may offer treatability advantages in species such as eastern hemlock and balsam-fir. However, two species, red maple and eastern spruce, proved moderately resistant to penetration with all of the preservatives, including CCA-C (Lebow et al. 2005). Decking specimens exposed above-ground in Wisconsin have been durable for all preservative/species combinations for 10 years (Lebow and Halverson 2015). The decking evaluation also indicated that appearance and dimensional stability concerns may lessen the desirability of red maple and balsam fir for use as decking. In contrast, the dimensional stability of eastern white pine appeared to make it the northeastern species most suitable for use in decking. Stake tests were also installed in southern Mississippi to evaluate the ground-contact durability of the wood species/preservative combinations. A detailed report was prepared on the results of this stake test after 5 years of exposure (Lebow et al. 2010a). However, at that time relatively little deterioration had occurred in treated specimens. This paper summarizes the ground-contact stake test results after 12 years of exposure, allowing a greater distinction in durability of the treated wood species.

\section{MATERIALS AND METHODS}

Specimens of eastern white pine, eastern spruce, balsam fir, eastern hemlock and red maple lumber for the study were supplied by cooperating mills. Lumber of the southern pine species group (primarily Pinus taeda, loblolly pine) was obtained through FPL for comparison. The same lumber was used to prepare the treatability specimens described in a previous study (Lebow et al. 2005) and the stake specimens described in this study. Southern pine species are by far the most commonly treated species in the United States, largely because their wide zone of readily treated sapwood (Lebow 2010). The northeastern softwoods evaluated in this study typically have a lower proportion of sapwood than southern pine, which may lessen their treatability. Although the sapwood of white pine is readily treated, the sapwood in balsam-fir, eastern spruce and eastern hemlock is thought to be less treatable than that of southern pine (Cooper and Morris 2007). Red maple has a relatively large proportion of sapwood (Wullschleger et al. 2001) but a previous study found that preservative penetration in red maple was less than that of the pine species (Lebow et al. 2005). 


\section{Specimen preparation}

Four hundred and twenty stakes $(19 \times 19 \times 457 \mathrm{~mm})$ were cut for each wood species/preservative combination and conditioned to constant weight in a room maintained at $23^{\circ} \mathrm{C}$ and $65 \%$ relative humidity. The stakes were weighed and then sorted into 16 groups of 25 and one group of 20 (4 preservatives at 4 concentrations plus an additional 20 untreated stakes) so that each group had similar density distributions. An additional set of 400 incised specimens was also prepared for all species except southern pine. The incised stakes were cut from the narrow edge of lumber specimens that had an incising density of approximately 3100 incisions $/ \mathrm{m}^{2}$, with incision length ranging from 12 to $15 \mathrm{~mm}$, and incision depth ranging from 5 to $9 \mathrm{~mm}$. The resulting dimensions of the incised stakes was $19 \times 38$ $\mathrm{x} 457 \mathrm{~mm}$. Because these stakes were cut from incised lumber, one face of the stakes was not incised. This differs from commercial practice in which all 4 surfaces are incised. The 25 stakes per treatment group were treated with chromated copper arsenate, copper citrate, alkaline copper quat or copper azole wood preservative. The formulations were provided by cooperating preservative manufacturers and were in compliance with the relevant AWPA standards at the time the project was initiated.

Chromated Copper Arsenate Type C (CCA-C). Actives composition of 47,5\% $\mathrm{CrO}_{3}, 18,5 \%$ copper (expressed as $\mathrm{CuO}$ ), and $34,0 \% \mathrm{As}_{2} \mathrm{O}_{5}$. CCA-c was evaluated at solution concentrations of 0,$36 ; 0,66$; 1,14 and 1,71 percent. CCA-C was used as a reference preservative because of its long history of use in pressure-treatment of southern pine wood products.

Alkaline Copper Quat Type C (ACQ-C): Actives composition of 66,7\% copper (expressed as $\mathrm{CuO}$ ) and 33,3\% alkylbenzyldimethyl ammonium compound. The copper is solubilized in a solution of ethanolamine and water. ACQ was evaluated at solution concentrations of $0,29,0,71,1,14$ and 1,71\%.

Copper Azole Type A(CBA-A): Actives composition of $49 \% \mathrm{Cu}, 49 \% \mathrm{H}_{3} \mathrm{BO}_{3}$ and $2 \%$ tebuconazole. The copper in this formulation is solubilized in a solution of ethanolamine and water. CBA-A was evaluated at solution concentrations of 0,$21 ; 0,52 ; 0,84$ and $1,26 \%$. Note that lower concentrations of CBA-A (relatively to the other three preservatives) were inadvertently used in this study because of a dilution error. $\mathrm{CBA}-\mathrm{A}$ is not currently in commercial use but is similar to the current copper azole Types B and C (CA-B and CA-C).

Ammoniacal Copper Citrate (CC): Actives composition of $66,7 \%$ copper (expressed as $\mathrm{CuO}$ ) and $33,3 \%$ citric acid. The copper is solubilized in a solution of ammonia and water. CC was evaluated at solution concentrations of 0,$29 ; 0,71 ; 1,14$ and $1,71 \%$. CC is no longer in commercial use but represents a copper-based system using ammonia to assist in solubilizing the copper.

All treatments were conducted using a full-cell pressure process. The initial vacuum was maintained at $-75 \mathrm{kPa}$ (gauge) for $30 \mathrm{~min}$; the pressure was maintained at 1,03 $\mathrm{MPa}$ (gauge) for 1 hour. Each stake was weighed before and after treatment to determine the amount of solution uptake. Following treatment the stakes were stacked in plastic bags for one week, and then allowed to air-dry under room conditions. Although the extent of fixation was not chemically evaluated in these stakes, the post-treatment conditioning period ensured that fixation had time to occur. Twenty stakes treated with each solution were assigned to the exposure plot in Mississippi, while the remaining 5 were reserved for assay of preservative retention. The results of the assay analysis were discussed in an earlier report (Lebow et al. 2010a) and are not presented in this paper.

\section{Stake Installation and Inspection}

The Mississippi plot is located within Harrison Experimental Forest (approximately 15 miles north of Gulfport-Biloxi). The location is within the American Wood Protection Association (AWPA) Deterioration Zone 5, which is considered a severe deterioration hazard (AWPA 2017a). Annual rainfall and temperatures at the site average $1750 \mathrm{~mm}$ and $20 \mathrm{C}$, respectively. The stake specimens were installed in an open field adjacent to forested areas. Because of the large number of stakes and large area of the plot there was some concern that the severity of the exposure may vary spatially within the plot. To address this concern the stakes were installed in repeating sets of treatment groups, with the order randomized within each set. The stakes were placed in rows with $305 \mathrm{~mm}$ spacing between stakes and $915 \mathrm{~mm}$ between rows. A $25 \mathrm{~mm}$ diameter power auger was used to drill holes to a depth of $229 \mathrm{~mm}$, allowing the stakes to be buried vertically to $1 / 2$ their length. The stakes were inspected at 1 , 
$2,3,4,5,8,10$ and 12 years after installation, with inspections occurring in the months of February or March. At each inspection the stakes were scraped lightly to remove soil and given a visual rating for decay and/or termite attack according to AWPA Standard E7 (Table 1) (AWPA 2003a). Ratings were summarized by calculating averages, percent stakes remaining, and number of stakes assigned to each rating category.

Table 1. Rating scheme for evaluation of stakes.

\begin{tabular}{|c|c|}
\hline Rating & Description of Stake Condition \\
\hline 10 & No evidence of attack \\
\hline 9 & Slight attack, up to $3 \%$ of cross-sectional area. \\
\hline 8 & Moderate attack, up to $10 \%$ of cross-sectional area. \\
\hline 7 & Moderate to severe attack, up to $30 \%$ of cross-sectional area. \\
\hline 6 & Severe attack, up to $50 \%$ of cross-sectional area. \\
\hline 4 & Very severe attack, up to $75 \%$ of cross-sectional area. \\
\hline 0 & $\begin{array}{l}\text { Failure. Can be broken easily by hand or the evaluation probe can penetrate through } \\
\text { stake. }\end{array}$ \\
\hline
\end{tabular}

\section{RESULTS AND DISCUSSION}

The majority of untreated stakes failed within 3 years regardless of wood species, although a few stakes persisted 4 or even 5 years (Figure 1). The rate of failures in southern pine stakes was somewhat less rapid than that observed for other studies in adjacent forested plots, which could be at least in part attributed to lower termite pressure in the open field. The untreated red maple and eastern hemlock stakes appeared to fail most rapidly, but it is evident that none of these wood species have significant natural durability when placed in ground contact.

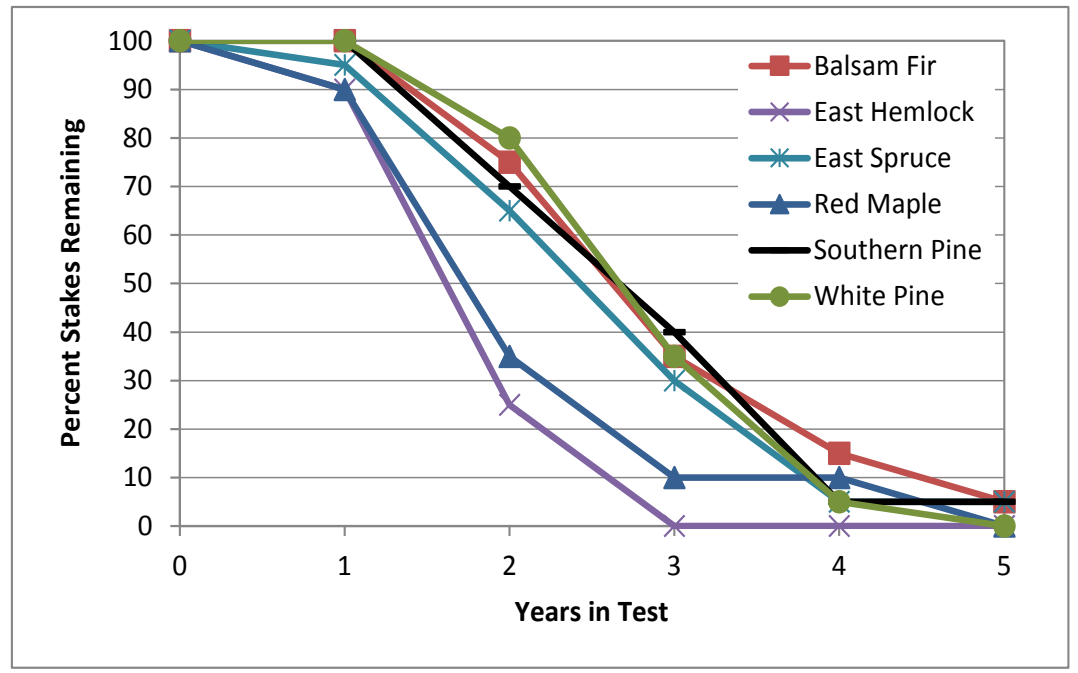

Figure 1. Longevity of untreated stakes. None of the untreated stakes were incised.

Among preservative-treated stakes, red maple and eastern spruce were most vulnerable to decay fungi and termites, respectively (Figure 2, Figure 3). Treated white pine, eastern hemlock and incised balsam-fir were more durable, with decay and termite ratings similar to southern pine. Overall, decay caused greater deterioration of the test stakes than termites for all wood species and retention groups. This is typical even for forested tests at this site, and termite attack appeared to be more localized in the 
open field used in this study. As expected, durability increased with increasing solution concentration and the resulting increase in preservative retention. A few failures were still observed in the highest retention grouping, especially in red maple and eastern spruce. However, it is important to note that each of these groups represents a range of preservative retentions, and that retentions vary between species and between preservatives. Incising did appear to result in a slight increase in durability with some species/retention level combinations, but the affect was not dramatic. This may in part be a result of only 3 of the 4 sides of each stake being incised. Incising appeared to provide little benefit for white pine, perhaps because the sapwood of white pine is relatively treatable.

CCA-C appeared to be slightly more effective than the copper-based preservatives in protecting northeastern species, especially at lower retentions (Figure 4). However durability of red maple lagged substantially below that of the other species for all retentions, and this trend was even more apparent with the copper-based preservatives. The extent of degradation in red maple does not appear to be solely attributable to poor treatment quality, as average red maple retentions were similar to other species. Previous studies have noted that waterborne copper-based preservatives can be less effective in protecting hardwoods than softwoods, possibly because of differences in the micro distribution of copper within the wood structure (Butcher 1979, Daniel and Nilsson 1987, Merrick et al. 2008, Smith et al. 1996).
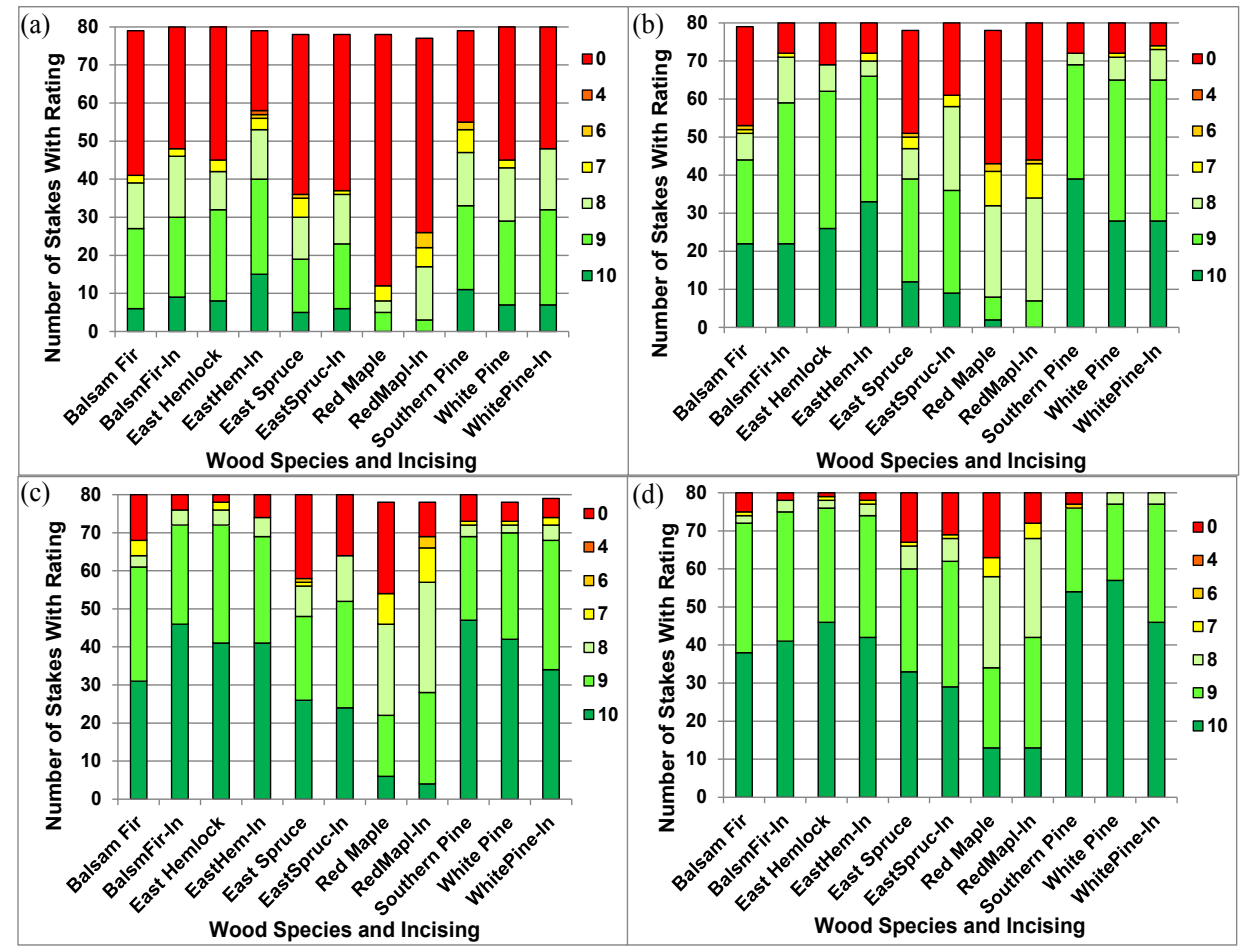

Figure 2. Number of stakes by decay rating after 12 years of exposure for the (a) low, (b) mediumlow, (c) medium-high, and (d) high retention groupings, preservatives combined. Ratings range from " 0 " (failure) to " 10 " (no attack). "In" indicates incised.

Incised eastern spruce tended to have lower average decay ratings than other softwood species, perhaps because of its relatively low preservative uptake (Figure 4). Previous researchers have also reported that CCA-treated eastern and western white spruce stakes exposed in Florida had more failures than other softwood species (Richards and McNamara 1997). They attributed these failures at that site to poor preservative penetration. Woodward et al. (2011) also reported poor performance of unincised ACA treated eastern spruce stakes exposed in Mississippi, but noted improved performance when stakes were incised. In this study, the performance of incised eastern spruce did improve with 
higher retentions, suggesting that a combination of poor penetration and low retention contributed to the lack of decay resistance. Additionally, the relatively high incidence of termite attack in eastern spruce (Figure 3) may also be a function of limited preservative penetration. Adequate treatment of eastern spruce may require use of alternative preservative formulations or more complex pretreatment conditioning methods (Hermoso and Vega 2016).

Preservative penetration is an important factor in stake durability (Tripathi and Poonai 2015), but it is somewhat difficult to distinguish the contributions of retention versus penetration in this test. Although not evaluated for the stakes used in this study, preservative penetration was evaluated in an earlier treatability study of lumber specimens cut from the same material (Table 2). It should be noted that the data shown in Table 2 is for lumber specimens that were incised on all 4 sides, whereas the stakes in this study were incised on only 3 sides. Penetration in eastern spruce did improve with incising, but remained well below of that of other species (Table 2). In the case of eastern spruce this could have resulted in only limited penetration on one side of the stake, perhaps creating an area of vulnerability. During inspections there was no obvious trend of termite or fungal attack originating on the unincised face of the incised spruce specimens, but this would have been difficult to detect after the attack progressed. Red maple also had less penetration than some of the other species, and showed little improvement with incising. However, because the test stakes have small dimensions $(19 \mathrm{x} 19$ $\mathrm{mm}$ ) only $9,5 \mathrm{~mm}$ of penetration would have been required to achieve complete treatment. In addition, unlike larger lumber or timber specimens that may form drying checks during exposure, there was no ready path for decay fungi or termites to penetrate through the outer layer of treatment. Thus, it seems likely that retention played a larger durability role than did penetration, with the possible exception of eastern spruce.

Table 2. Depth of preservative penetration $(\mathrm{mm})$ observed in lumber specimens in an earlier study, average of all preservatives (Lebow et al. 2005).

\begin{tabular}{|l|c|c|c|c|c|c|c|}
\hline \multicolumn{2}{|c|}{} & $\begin{array}{c}\text { Balsam } \\
\text { Fir }\end{array}$ & $\begin{array}{c}\text { Eastern } \\
\text { Hemlock }\end{array}$ & $\begin{array}{c}\text { Eastern } \\
\text { Spruce }\end{array}$ & $\begin{array}{c}\text { Red } \\
\text { Maple }\end{array}$ & $\begin{array}{c}\text { Southern } \\
\text { Pine }\end{array}$ & $\begin{array}{c}\text { White } \\
\text { Pine }\end{array}$ \\
\hline Not incised & Average & 10,2 & 14,1 & 3,3 & 9,8 & 36,6 & $\begin{array}{c}\text { Not } \\
\text { evaluated }\end{array}$ \\
\hline & Std. Dev. & 11,9 & 12,3 & 3,7 & 11,1 & 10,3 & \\
\hline & & & & & & & \multirow{2}{*}{$\begin{array}{c}\text { Not } \\
\text { Incised }\end{array}$} \\
\cline { 1 - 6 } & Average & 15,7 & 23,1 & 6,3 & 9,9 & 30,4 \\
\hline & Std. Dev. & 10,5 & 12,3 & 3,9 & 10,1 & evaluated & 11,1 \\
\hline
\end{tabular}

Note: The stakes evaluated in the current study were cut from the same material.

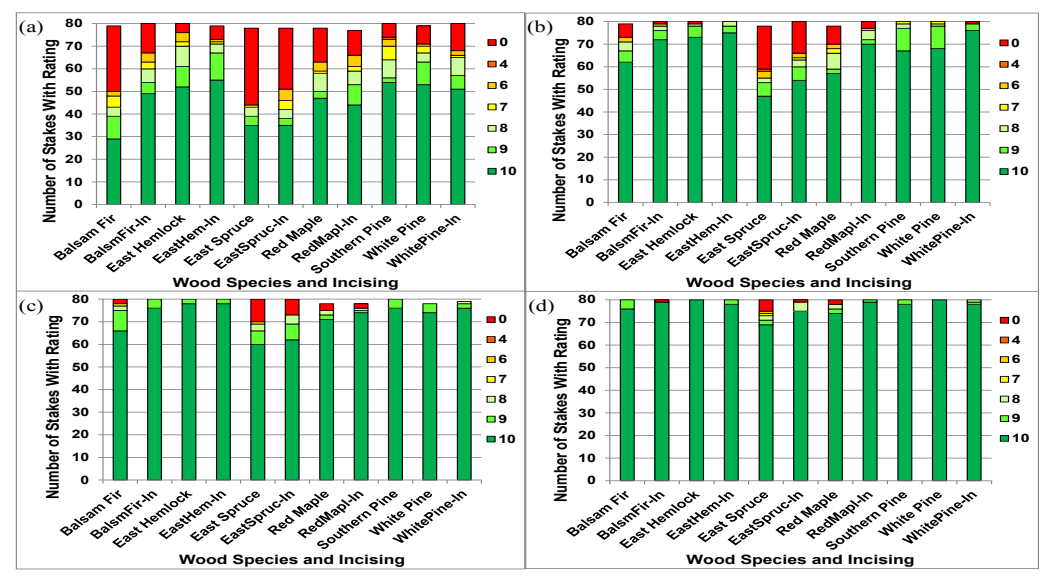

Figure 3. Number of stakes by termite rating after 12 years of exposure for the (a) low, (b) mediumlow, (c) medium-high, and (d) high retention groupings, preservatives combined. Ratings range from "0" (failure) to "10" (no attack). "In" indicates incised. 
In contrast to red maple and eastern spruce, the unincised white pine and the incised balsam-fir and eastern hemlock stakes had decay resistance comparable to southern pine for all but the lowest retentions. The copper-based preservatives appeared to provide similar protection when compared at similar retentions, although durability of the CC treated stakes appeared lower in some cases. It should be noted that many retentions evaluated in this study are well below those specified for protection of southern pine lumber placed in contact with the ground. At the time this research was initiated AWPA standards specified minimum ground-contact retention of $6,4 \mathrm{~kg} / \mathrm{m}^{3}$ for ACQ-C, CCA-C and CC, and $6,5 \mathrm{~kg} / \mathrm{m}^{3}$ for CBA-A (AWPA 2003b). Some of the retentions (for the CBA-A treatment for example) are lower than anticipated and this should be considered when reviewing the durability data.
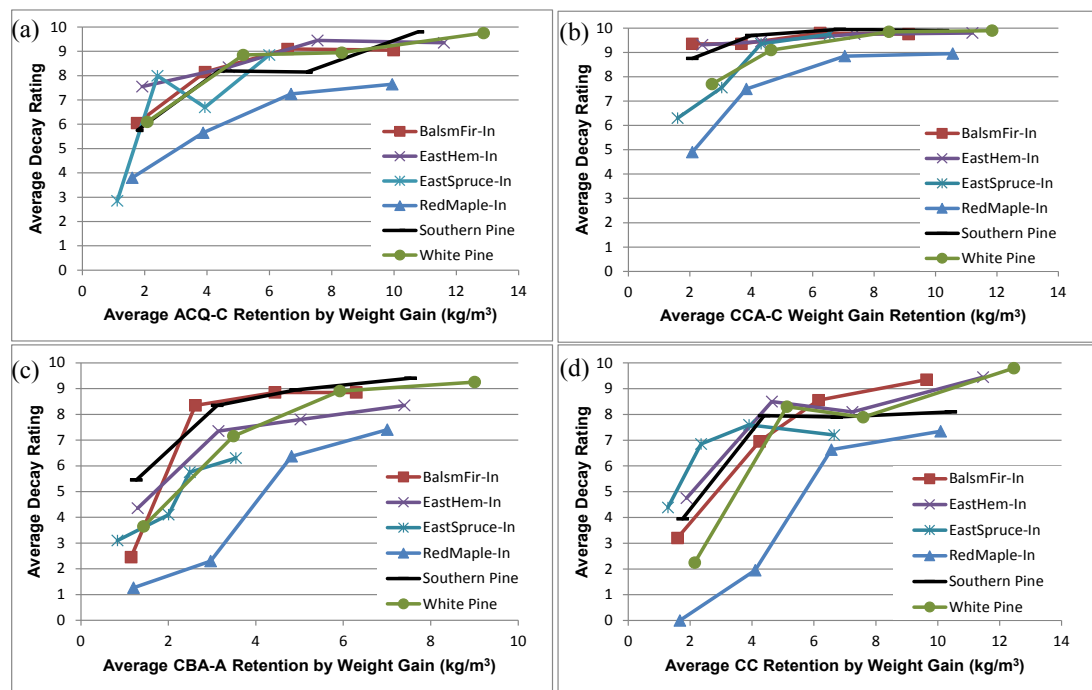

Figure 4. Average decay ratings (year 12) versus average group retention for (a) ACQ-C, (b) CCA-C, (c) CBA-A and (d) CC treated stakes. For clarity the data presented is limited to the unincised stakes for the treatable pine species and incised stakes for the less treatable species. Ratings range from " 0 " (failure) to "10" (no attack). "In" indicates incised.

It should also be noted that factors other than durability can influence the selection of wood species for preservative treated structural lumber. Eastern hemlock, eastern white pine and balsamfir all have lower mechanical properties than southern pine species, and balsam-fir has a relatively high moisture content which requires longer drying times than other northeastern species (Sinclair and Barnes 1984). Eastern hemlock trees also often suffer from "ring shake", a condition where the wood separates longitudinally parallel to the annual growth rings (Baumgras et al. 2000), and may not meet grade requirements for some structural applications. A positive attribute of eastern white pine is its dimensional stability, which could result in less warping relative to southern pine when used in applications such as decking (Lebow and Halverson 2015).

When viewed over exposure time it appears that, when treated to approximate ground-contact retentions, the wood species were relatively similar in durability until about 5 years of exposure (Figure 5). By the year 8 inspection, average decay ratings for the red maple and eastern spruce stakes had separated below those of the other species. The most notable decline in the average decay rating of the more durable species occurred between 8 - 10 years, with a subsequent lesser decline between 10 and 12 years. These trends do not appear to be function of climate, which was relatively typical during those years. The trends over time highlight the difficulty in utilizing short-term stake tests to evaluate the long term durability of treated wood. The average decay ratings of the red maple and eastern spruce stakes were relatively strong (9,7 and 9,8 respectively) after 5 years, whereas AWPA guidelines (AWPA $2017 \mathrm{~b}$ ) indicate that as few as 3 years of testing may suffice in high decay hazard areas such as southern Mississippi.

The small stakes used in durability evaluations are intended to accelerate deterioration relative to larger in-service members, but the extent of the acceleration is not always clear. A review that 
compared the durability of matched 19 by $19 \mathrm{~mm}$ to 38 by $89 \mathrm{~mm}$ (nominal " 2 by 4 " lumber) stakes found that it took the lumber-sized stakes an average of 2,2 times longer to fail, but that the relationship between two the stake sizes varied substantially. Linear regression of average years to failure for the two stake sizes across multiple test plots yielded an $\mathrm{R}^{2}$ value of only 0,69 (Lebow et al. 2010b). In this study it is possible that the small stakes underestimated the value of incising relative to larger productsize material which would have a larger proportion of untreated interior wood. Smaller stakes may also exaggerate the effect of preservative leaching relative to product-sized material (Bahmani et al. 2016).

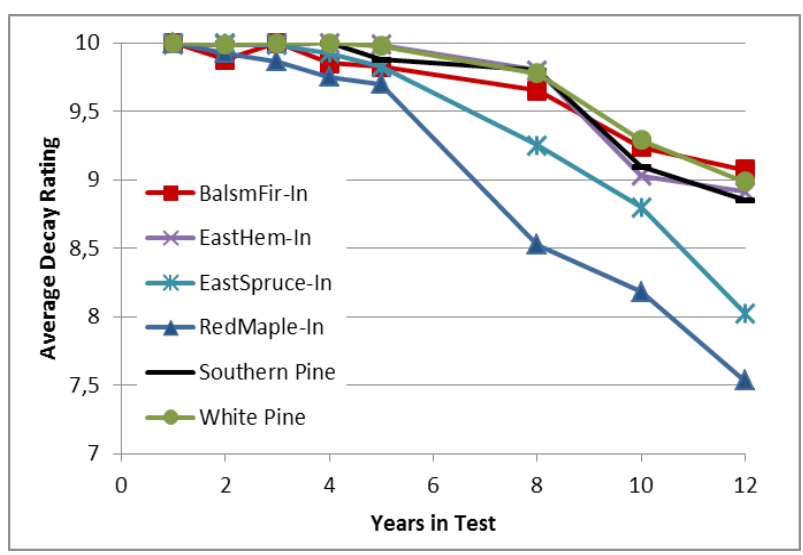

Figure 5. Average decay rating by year, preservatives combined. To best approximate ground-contact retentions, the highest retention grouping was used for CBA-A treated stakes and for eastern spruce stakes treated with all preservatives. The second highest retention grouping was used for all other preservative/species combinations. Ratings range from "0" (failure) to "10" (no attack). "In" indicates incised.

\section{CONCLUSIONS}

Eastern white pine, incised eastern hemlock, and balsam-fir had durability similar to southern pine when treated with CCA or the copper-based preservatives. Although the copper-based preservatives appeared to be slightly less effective than CCA, especially at lower retentions, they provided adequate protection at higher retentions. Eastern spruce was less durable than the other softwood species, apparently because of a combination of poor preservative uptake and penetration. Eastern spruce was also the species most vulnerable to termite attack, although decay caused much more damage than termites for all wood species and preservative treatments. Red maple had the poorest durability at all retentions and for all preservatives. Retentions in red maple were similar to other species, and the low durability may be attributable to the effect of hardwood anatomy on uniformity of preservative distribution within the wood structure. Incising appeared to provide a slight durability benefit for some species, but had little effect on the durability of the more treatable eastern white pine. It is feasible that incising would have provided a greater benefit if all four sides of the stakes were incised, and is likely to provide greater benefit in larger commodity-sized material. This study indicates that several northeastern softwoods can be adequately durable when pressure-treated with CCA-C or copper-based preservatives. Imparting durability to red maple require use of higher preservative retentions or the use of different types of preservatives. In addition to durability, characteristics such as strength or dimensional stability may impact the suitability of these species for use in treated structural products.

\section{REFERENCES}

Alderman, D.R.; Bumgardner, M.S.; Baumgras, J.E. 2005. An assessment of red maple resources in the northeastern United States. Northern J Appl For 22:181-189.

AWPA. 1997. Standard C2. Lumber, timbers, bridge ties and mine ties- treatment by pressure processes. Book of Standards. American Wood Preservers Association, Granbury, TX. 391p. 
AWPA. 2003a. Standard E7. Standard Method of Evaluating Wood Preservatives by Field Tests with Stakes. Book of Standards. American Wood Preservers' Association. Selma, AL. 522p.

AWPA. 2003b. U1-03. Use Category System: User Specification For Treated Wood. Commodity Specification A, Sawn Products. Book of Standards. American Wood Preservers' Association. Selma, AL. 522p.

AWPA. 2017a. U1-17. Use Category System: User Specification for Treated Wood. Commodity Specification D: Poles. Book of Standards. American Wood Protection Association, Birmingham, AL. $624 p$.

AWPA. 2017b. Guidance Document A: Data Requirement Guidelines for Listing Wood Preservatives in the AWPA Standards. Book of Standards. American Wood Protection Association, Birmingham, AL. 624p.

Baumgras, J.E.; Sendak, P.E; Sonderman, D.L. 2000. Ring shake in eastern hemlock: frequency and relationship to tree attributes. Proceedings: Symposium on Sustainable Management of Hemlock Ecosystems in Eastern North America (eds K.A.McManus, K.S.Shields and D.R.Souto), pp. 156-160. USDA General Technical Report 267. USDA Newtown Square, PA.

Bahmani, M.; Schmidt, O.; Fromm, J.; Melcher, E. 2016. Influence of wood sample size and species on the leaching of chromium and copper using different lab tests. Maderas-Cienc Tecnol 18(2):265-272.

Butcher, J.A.1979. Soft rot control in hardwoods treated with chromated copper arsenate preservatives. Part V: A reason for the variable performance of CCA treated hardwoods. Material und Organismen 14(3):215-234.

Cooper, P.; Morris, P. 2007. Challenges in treating Canadian species. Proc. $28^{\text {th }}$ Annual Meeting of the Canadian Wood Preservation Association. Quebec City, Quebec. 28:9-20.

Daniel, G.; Nilsson, T. 1987. Comparative studies on the distribution of lignin and CCA elements in birch using electron microscopic x-ray microanalysis. IRG/WP/1328. Inter. Res. Group on Wood Preservation, IRG Secretariat, Stockholm, Sweden. 19p.

Department of Environmental Conservation. 2015. Stumpage Price Report. Summer 2015/\#87. New York Department of Environmental Conservation, Division of Lands and Forests: Albany, NY. 2p. $<$ http://www.dec.ny.gov/docs/lands_forests_pdf/spr2015summer.pdf.> [Accessed December, 2015].

Fei, S.; Steiner, K.C. 2007. Evidence for Increasing Red Maple Abundance in the Eastern United States. Forest Science 53(4):473-477.

Gjovik, L.R.; Schumann, D.R. 1992. Treatability of native softwood species of the northeastern United States. Res. Pap. FPL-RP-508. Madison, WI: U.S. Department of Agriculture, Forest Service, Forest Products Laboratory. 20 p.

Hermoso, E.; Vega, A. 2016. Effect of microwave treatment on the impregnability and mechanical properties of Eucalyptus globulus wood. Maderas-Cienc Tecnol 18(1):55-64.

Lebow, S.T. 2010. Chapter 15. Wood Preservation. In: Wood Handbook - Wood as an Engineering Material. General Technical Report FPL-GTR-190. Madison, WI: U.S. Department of Agriculture, Forest Service, Forest Products Laboratory. 508p.

Lebow, S.T.; Halverson, S.A. 2015. Performance of Northeastern United States wood species treated with copper based preservatives: 10 year above-ground decking evaluation. International Wood Products Journal 6(2):72-78.

Lebow, S.T.; Halverson, S.A.; Hatfield, C.A. 2005. Treatability of underutilized northeastern species with CCA and alternative wood preservatives. Research Note FPL-RN-0300. Madison, WI: U.S. Department of Agriculture, Forest Service, Forest Products Laboratory. 5 p. 
Lebow, S.T.; Woodward, B.M.; Halverson, S.A.; Arango, R.A. 2010a. Stake tests of Northeastern species treated with copper-based preservatives: Five-year results. Research Note FPL-RN-0314. Madison, WI: U.S. Department of Agriculture, Forest Service, Forest Products Laboratory. 17 p.

Lebow, S.; Hatfield, C.; Evans, J. 2010b. A comparison of the durability of two stake sizes in southern Mississippi. Proc., $105^{\text {th }}$ Annual Meeting of the American Wood Protection Association, April 19-21, 2009, San Antonio, TX. 105:66-72.

Merrick, P.G.; Freeman, M.H.; Brient, J.M. 2008. Field Stake Performance of Parallel Strand Lumber Treated with Waterborne Copper Naphthenate. Doc. No. IRG/WP 08-40435. Inter. Res. Group on Wood Preservation, IRG Secretariat, Stockholm, Sweden. 8p.

Morris, P. I.; Stirling, R.; Ingram, J. 2017. Ten-Year Performance of Stakes and Decking Treated with Copper Azole Type B and Alkaline Copper Quat Type D (Carbonate). Forest Products Journal 67(1):13-23.

Richards, M.J.; Inwards, R.D. 1989. Treatability with CCA and initiation of field performance testing of refractory softwoods. Proc. $10^{\text {th }}$ Annual Meeting of the Canadian Wood Preservation Association. Vancouver, B.C. 10:144-178.

Richards, M.J.; McNamara, W.S. 1997. The field performance of CCA-C treated sawn refractory softwoods from North America. IRG/WP/40085. Inter. Res. Group on Wood Preservation, IRG Secretariat, Stockholm, Sweden. 26p.

Sinclair, S.A; Barnes, D.P. 1984. Spruce Budworms Handbook: Balsam Fir: Its Properties and Utilization. Handbook No. 629, United States Dept. of Agriculture, Washington, D.C. 69p.

Smith, W.B. 1986. Treatability of several northeastern species with chromated copper arsenate wood preservative. Forest Prod J 36(7/8):63-69.

Smith, W.B.; Abdullah, N.; Herdman, D.; DeGroot, R.C. 1996. Preservative treatment of red maple. Forest Prod J 46(3):35-41.

Smith, W. B.; Miles, P. D.; Perry, C. H.; Pugh, S. A. 2009. Forest Resources of the United States, 2007. Gen. Tech. Rep. WO-78.Washington, DC: U.S. Department of Agriculture, Forest Service, Washington Office. 336 p.

Tripathi, S.; Poonia, P.K. 2015. Treatability of Melia composita using vacuum pressure impregnation. Maderas-Cienc Tecnol 17(2):373-384.

University of Massachusetts Extension. 1994. Southern New England Stumpage Price Survey Results. Second Quarter-2105. University of Massachusetts Extension, Department of Environmental Conservation. 1p. <http://masswoods.net/price-report/southern-new-england-stumpage-price-report1994-present.> [Accessed December, 2015].

Woodward, B.M.; Hatfield, C.A.; Lebow, S.T. 2011. Comparison of wood preservatives in stake tests: 2011 progress report. Research Note FPL-RN-02. Madison, WI: U.S. Department of Agriculture, Forest Service, Forest Products Laboratory. 120 p.

Wullschleger, S.D.; Hanson, P.J.; Todd, D.E. 2001. Transpiration from a multi-species deciduous forest as estimated by xylem sap flow techniques. Forest Ecol Manage 143:205-213.

Wisconsin Department of Natural Resources. 2014. White Pine Report. 2014. Species Summaries. $<$ http://dnr.wi.gov/topic/ForestBusinesses/documents/WhitePineReport.pdf. $>$ [Accessed February, 2016.] 